Revista Brasileira de Agricultura Irrigada v.8, nº 5, p.411 - 421, 2014

ISSN 1982-7679 (On-line)

Fortaleza, CE, INOVAGRI - http://www.inovagri.org.br

DOI: $10.7127 /$ rbai.v8n500221

Protocolo 221.14 - 06/03/2014 Aprovado em 22/07/2014

\title{
VARIABILIDADE ESPACIAL E TEMPORAL DA QUALIDADE DAS ÁGUAS EM RESERVATÓRIO DA REGIÃO SEMIÁRIDA PARA FINS DE IRRIGAÇÃO
}

\author{
Maria Monaliza de Sales ${ }^{1}$, Fernando Bezerra Lopes ${ }^{2}$, Ana Célia Maia Meireles ${ }^{3}$, Luiz \\ Carlos Guerreiro Chaves ${ }^{4}$, Eunice Maia de Andrade ${ }^{5}$
}

\begin{abstract}
RESUMO
O presente trabalho objetivou avaliar a qualidade sazonal das águas para uso na agricultura irrigada do reservatório de Orós, inserido na região semiárida do Estado do Ceará. Os dados empregados nesta pesquisa foram coletados entre março de 2011 e dezembro de 2012, em 20 pontos do reservatório. O estudo considerou as seguintes variáveis: condutividade elétrica da água (CE), concentrações de cálcio, magnésio e sódio e posteriormente calculada a razão de adsorção de sódio (RAS). Os resultados mostraram que as águas do reservatório apresentaram, tanto no período seco como chuvoso, valores

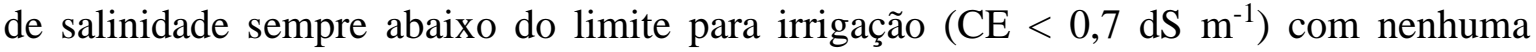
restrição para o uso na agricultura irrigada. A estação chuvosa, apesar de menor variação espacial dos pontos de coletas em relação a estação seca, foi observado maiores valores de CEa, variando de $0,2 \mathrm{dS} \mathrm{m}^{-1}$ a $0,35 \mathrm{dS} \mathrm{m}^{-1}$ e para a estação seca a variação foi de $0,11 \mathrm{dS}$ $\mathrm{m}^{-1}$ a $0,34 \mathrm{dS} \mathrm{m} \mathrm{m}^{-1}$. De acordo com a classificação para irrigação do USDA as águas do reservatório apresentaram classificadas como $\mathrm{C}_{1} \mathrm{~S}_{1}$ e $\mathrm{C}_{2} \mathrm{~S}_{1}$, tanto no período seco como chuvoso, apresentando risco de salinidade baixo a médio e risco de sodicidade baixo.
\end{abstract}

Palavras-chave: água superficial, condutividade elétrica, razão de adsorção de sódio.

\section{SPATIAL AND TEMPORAL VARIABILITY OF WATER QUALITY FROM RESERVOIR IN THE SEMIARID REGION FOR IRRIGATION ABSTRACT}

This study aimed to evaluate the quality of seasonal water use for irrigated agriculture in the reservoir Orós, inserted in the semiarid region of the State of Ceará. The data used in this study were collected between March 2011 and December 2012, 20 points in the

\footnotetext{
${ }^{1}$ Graduanda em Irrigação e Drenagem - IFCE, Campus Iguatu, Ceará, Brasil. monnallysa2011@hotmail.com ${ }^{2}$ Doutor em Engenharia Agrícola, Bolsista PNPD/CAPES do Dep. de Eng. Agrícola, CCA/UFC, Fortaleza, CE, lopesfb@yahoo.com.br

${ }^{3}$ D.Sc., Bolsista Pós-Doutorado/CNPq, Université du Maine, França, ameireles2003@yahoo.com.br

${ }^{4}$ Doutorando em Engenharia Agrícola, Depto. de Engenharia Agrícola, UFC, Fortaleza, CE, luizcarlosguerreiro@gmail.com

${ }^{5}$ Ph. D., Prof ${ }^{a}$ do Depto. de Engenharia Agrícola, CCA/UFC, Fortaleza, CE, eandrade@ufc.br
} 
reservoir. The study included the following variables: electric conductivity (EC), concentrations of calcium, magnesium and sodium and subsequently calculated the sodium adsorption ratio (SAR). The results showed that the waters of the reservoir presented, both in the dry and rainy, salinity values always below the limit for irrigation $\left(\mathrm{EC}<0.7 \mathrm{dS} \mathrm{m}^{-1}\right)$ with no restriction for use in irrigated agriculture. The rainy season, although lower spatial variation of collection points over the dry season, it was observed that showed higher EC values ranging from 0.2 to $0.35 \mathrm{dS} \mathrm{m} \mathrm{m}^{-1}$ and the dry season ranged between 0,11 and 0.34 $\mathrm{dS} \mathrm{m} \mathrm{m}^{-1}$. According to the USDA classification for irrigation water reservoir had classified as C1S1 and $\mathrm{C}_{2} \mathrm{~S}_{1}$, both in the dry and rainy, with low risk of salinity in the medium and low risk of sodicity.

Keywords: surface water, electric conductivity, sodium adsorption ration.

\section{INTRODUÇÃO}

A água é um recurso natural de fundamental importância para a vida no planeta, sem ela não existe vida. Apesar deste fator tão importante, nos últimos anos a água tem se tornado elemento insuficiente para a população, isso decorrente do aumento populacional, assim como pelo mau uso deste recurso.

Em regiões semiáridas, o problema com a água tende a ser mais elevado, devido a escassez de água decorrente do déficit hídrico, as chuvas ocorrem apenas num período de três a cinco meses por ano e são irregularmente distribuídas no tempo e no espaço, aliada à ocorrência de altas taxas de evaporação, tornando responsável pela intermitência de quase toda a rede hidrográfica dessas regiões (FROTA JÚNIOR et al., 2006). Este fato representa um problema severo para a captação e armazenamento desse recurso, por tanto, milhares de reservatórios foram construídos nessas regiões, com a finalidade principal de armazenar água para consumo humano, usos domésticos, indústria, dessedentação de animais e agricultura irrigada, principalmente, durante os períodos de estiagem.

Embora os açudes contribuam significativamente para o abastecimento hídrico, essas regiões se deparam com um novo impasse: a qualidade das águas em muitos reservatórios não é adequada para os múltiplos usos. A agricultura irrigada, por exemplo, depende tanto da qualidade quanto da quantidade da água, no entanto, o aspecto qualidade tem sido desprezado (AYERS; WESTCOT, 1999).

Para se avaliar a qualidade da água, é de fundamental importância o monitoramento periódico dos corpos hídricos, tornando possível o conhecimento das alterações destas águas no decorrer do tempo e do espaço em função das intervenções humana no meio ambiente (LOPES et al., 2014a; LOPES et al., 2014b), como exemplos: desmatamento de matas ciliares e poluição decorrente do escoamento superficial de esgotos (GOMES et al., 2007; FRANCO e HERNANDEZ, 2009; VANZELA et al., 2010; LOPES et al., 2007; LOPES et al., 2008).

O conhecimento do teor total de sais solúveis (condutividade elétrica, CE) presentes na água, seus íons dominantes, bem como do teor de sódio em relação aos teores de cálcio e magnésio (razão de adsorção de sódio, RAS) permite a utilização e manejo da água de forma mais adequada (MEIRELES, 2007; LOPES et al., 2007; ARAÚJO NETO et al., 2010). O emprego de águas de boa qualidade com baixos níveis de salinidade e risco de sodicidade não deveriam oferecer maiores problemas à agricultura irrigada, no entanto, o inadequado 
balanço de sais comumente verificado em decorrência de problemas de drenagem, promove uma gradativa degradação dos solos irrigados e um progressivo aumento das áreas com problemas (FREIRE et al., 2003).

Nesse contexto, esse trabalho tem como objetivo avaliar a qualidade sazonal e espacial das águas para uso na agricultura irrigada do reservatório Orós, inserido na região semiárida do Estado do Ceará.

\section{MATERIAL E MÉTODOS}

O estudo foi desenvolvido no açude Orós (Barragem Presidente Juscelino Kubitschek de Oliveira), onde águas do Rio Jaguaribe são barradas próximas à divisa das bacias do Alto e Médio Jaguaribe, localizado no município de Orós, na região Centro-Sul Estado do Ceará (Figura 1). A bacia hidráulica do reservatório faz parte de três municípios cearenses: Iguatu, Quixelô, e Orós, distante cerca de $450 \mathrm{~km}$ de Fortaleza, capital do estado. A capacidade total de acumulação do reservatório é de aproximadamente 1,94 bilhões de metros cúbicos, a bacia hidrográfica do reservatório corresponde a aproximadamente 96\% da sub-bacia hidrográfica do Alto Jaguaribe, sendo ele o considerado o segundo maior reservatório do Ceará (Figura 1). $\mathrm{O}$ açude tem como finalidade o armazenamento de água para a região da sub-bacia do Alto Jaguaribe, a perenização do Vale do Jaguaribe, no trecho do Médio e Baixo Jaguaribe, além de propiciar o aumento das áreas irrigadas e possibilitar o desenvolvimento da piscicultura e aproveitamento de culturas na área de montante (DNOCS, 2014).

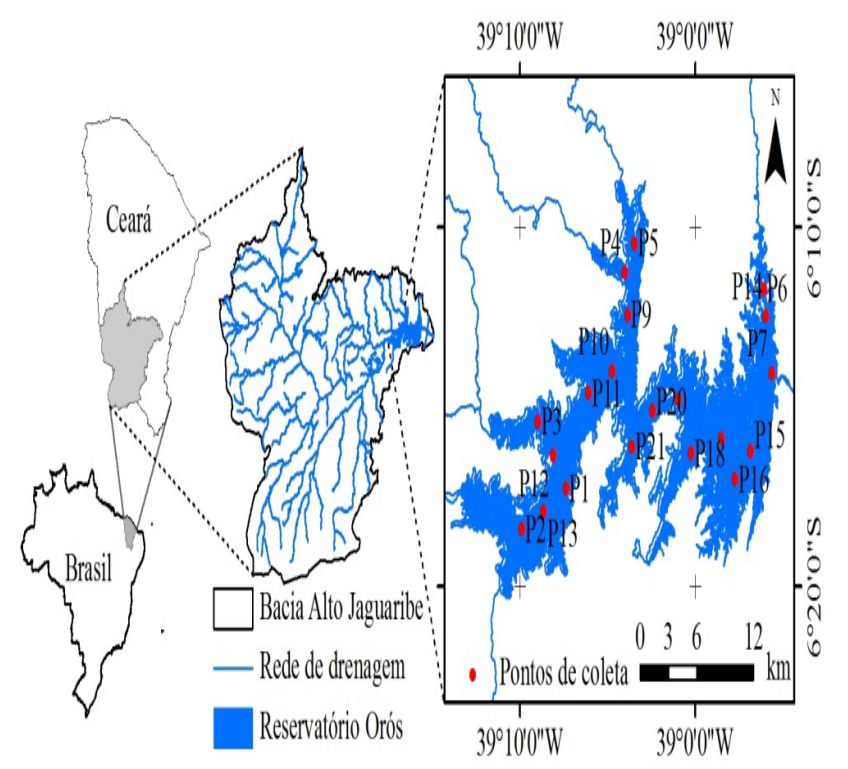

Figura 1. Localização do reservatório Orós, Ceará, com estações amostrais (Fonte: LOPES et al., 2014b).

Conforme a classificação de Köppen, a região apresenta clima do tipo BSw’h', semiárido quente com chuvas de verão e outono, e temperatura média mensal sempre superior a 18 ${ }^{\circ} \mathrm{C}$. O regime pluviométrico da bacia do Alto Jaguaribe, como em todo o Estado, se caracteriza por uma alta variabilidade espacial e temporal, portanto, a principal limitação com relação à pluviometria na região é em decorrência muito mais na irregularidade do regime do que da altura pluviométrica anual (ARRAES, 2010). As precipitações das cidades que ficam ao entorno do reservatório chegam a atingir valores médios anuais superiores a $800 \mathrm{~mm}$. Na Figura 2 estão representadas as precipitações pluviométricas mensais nos anos de estudos calculadas a partir da média das precipitações das estações de Orós e Iguatu, obtidas junto à Fundação Cearense de Meteorologia e Recursos Hídricos (FUNCEME, 2014). A evapotranspiração potencial média anual, medida através de Tanque Classe A em torno de 1988 mm (LOPES et al., 2014b). 


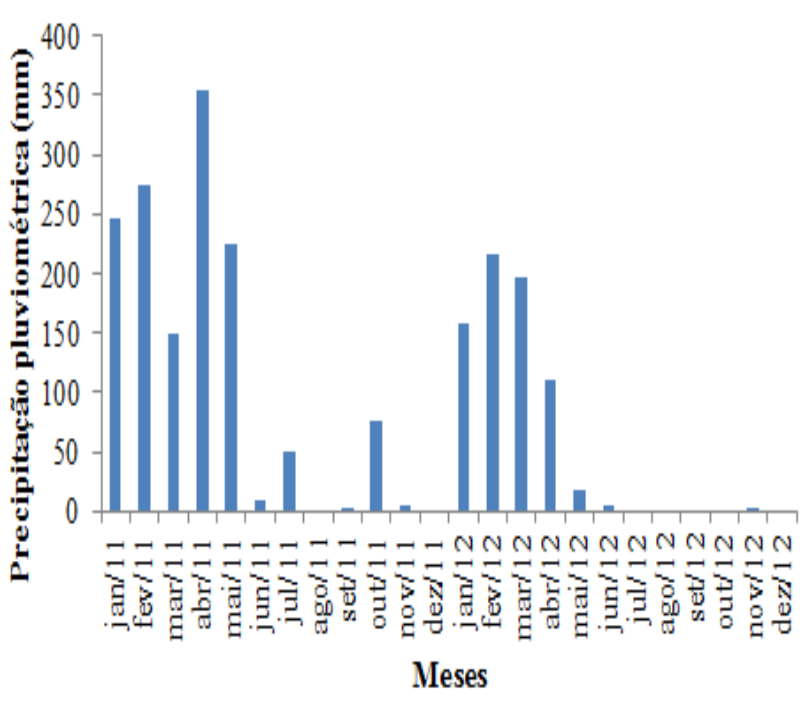

Figura 2. Precipitações pluviométricas mensais nos anos de estudos

O solo predominante na região das áreas no entorno do reservatório segundo a classificação da EMBRAPA (2006), são quatro as classes: os solos argissolo vermelho-amarelo eutrófico, os neossolos litólicos eutróficos, os vertissolos hidromórficos, e os solos litólicos eutróficos e distróficos.

As coletas foram realizadas na superfície d'água, na profundidade de 0,30 m, nos meses de março, junho, agosto e dezembro de 2011 e fevereiro, maio, agosto e dezembro de 2012, em 20 estações amostrais (Figura 1). Todos os pontos foram georreferenciados com o auxílio do GPS do modelo GPSMAP 62 Series.

Após cada coleta, as amostras foram dirigidas para o Laboratório de Água, Solo e Tecidos Vegetais (LABAS), do Instituto Federal de Educação, Ciência e Tecnologia do Ceará Campus Iguatu no qual foram analisadas segundo a metodologia da APHA (2005). Foram determinadas as variáveis: condutividade elétrica da água, concentrações de cálcio $\left(\mathrm{Ca}^{2+}\right)$, magnésio $\left(\mathrm{Mg}^{2+}\right)$ e sódio $\left(\mathrm{Na}^{+}\right)$.

A partir dos valores de $\mathrm{Na}^{+}, \mathrm{Ca}^{2+}$ e $\mathrm{Mg}^{2+}$ foi calculada a RAS com a seguinte expressão:

$$
\boldsymbol{R} \boldsymbol{A S}=\frac{N a}{\sqrt{\frac{C a+M g}{2}}}
$$

Onde:

Na: teor de sódio na água, $\mathrm{mmol}_{\mathrm{c}} \mathrm{L}^{-1}$;

$\mathbf{C a}^{\mathbf{o}}$ : teor de cálcio da água, $\mathrm{mmol}_{\mathrm{c}} \cdot \mathrm{L}^{-1}$

Mg: teor de magnésio na água, $\mathrm{mmol}_{\mathrm{c}} \mathrm{L}^{-1}$.

Com a utilização do software QUALIGRAF (FUNCEME, 2013), foi feita a classificação proposta pelo United States Department of Agricultural - USDA (RICHARDS, 1954), para os meses representativos das estações chuvosa e seca, que leva em consideração a CEa e a RAS, para verificar se a água apresentava algum perigo de salinização e/ou sodificação nos períodos estudados.

Na Tabela 1 verificam-se os padrões de qualidade de água para irrigação proposto pelo United States Department of Agricultural USDA (RICHARDS, 1954).

Tabela 1. Critérios para classificação da restrição de uso das águas superficiais do Estado do Ceará quanto aos parâmetros CE e RAS

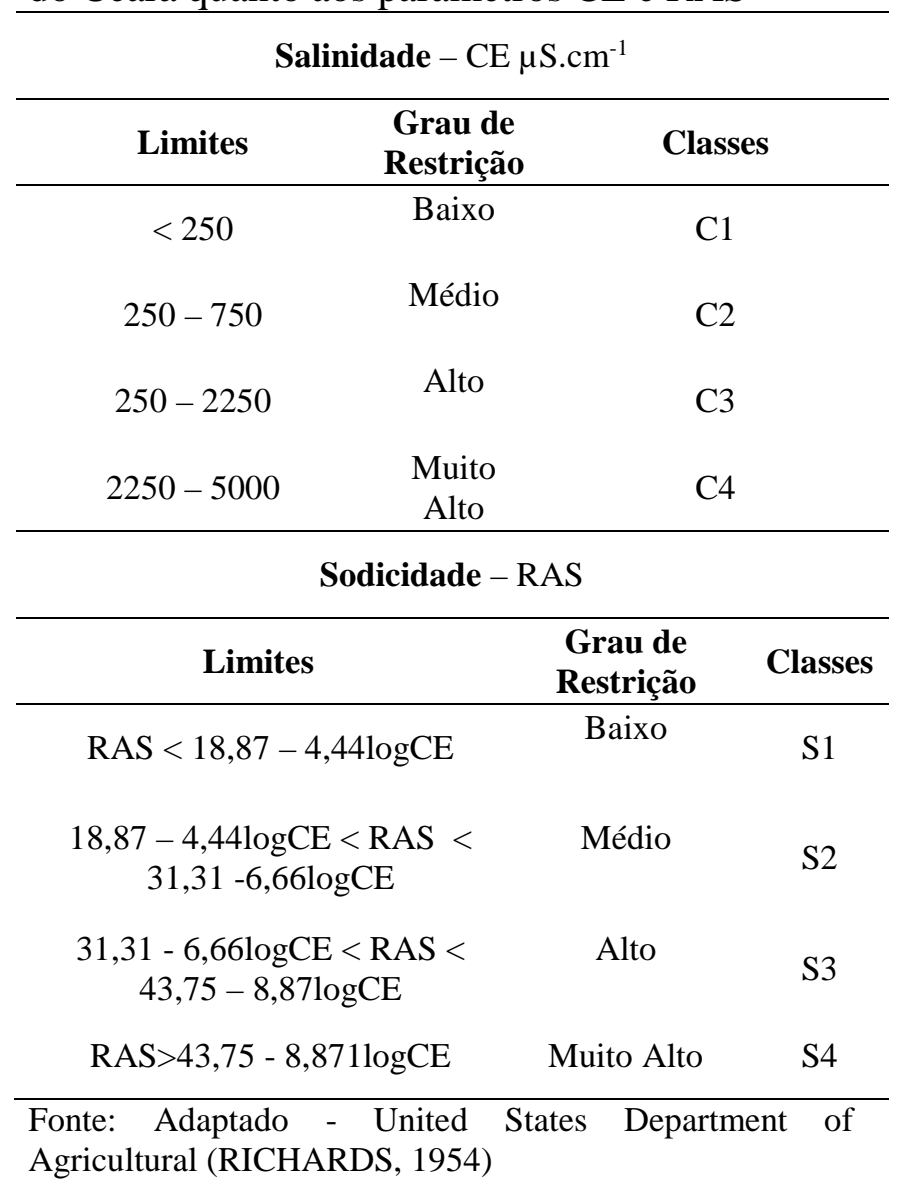


Para o tratamento estatístico dos dados e para se conhecer as características e o comportamento dos íons específicos, sua tendência central (mediana), a variabilidade de seus valores (amplitude, extremos, discrepantes) e percentil, desenvolveu-se uma análise exploratória pelo emprego da técnica de "Boxplot" com o uso do software do Statistical Package for Social Science for Windows - SPSS 16.0, visando auxiliar na caracterização do efeito da espacialização e temporal das águas superficiais do açude. As posições relativas da mediana, primeiro e terceiro quartil dão uma noção da assimetria da distribuição. Os comprimentos das caudas são dados pelas linhas que vão do retângulo aos valores discrepantes.

\section{RESULTADOS E DISCUSSÃO}

Verifica-se na Figura 3 a variação espacial da Condutividade Elétrica (CE) do açude Orós, no período seco e chuvoso. Em ambas as estações observaram-se variações no comportamento da CE, representados pela maior abertura das caixas, no entanto, apresentando valores sempre abaixo do limite para irrigação $\left(0,7 \mathrm{dS} \mathrm{m^{-1 }}\right)$ com nenhuma restrição para o uso na agricultura irrigada segundo Ayers e Westcot (1999).

Avaliando as variações espaciais nas estações secas e chuvosas, verificou-se para a estação seca maior variabilidade dos valores de CE nos pontos de coletas, representados pelas maiores aberturas das caixas, sendo apenas os pontos P01 e P13 os que apresentaram menores variações, com mediana em cima da linha do primeiro quartil, justificado pelo fato da não existência de agricultura irrigada no entorno destes pontos localizados próximos à comunidade Conceição. Já estes pontos apresentaram comportamento contrário na estação chuvosa, no qual ocorreu uma maior abertura das caixas e consequentemente maior variação da salinidade, assim como maior concentração dos sais, isso devido serem influenciados pelo ponto P02, que é a entrada principal do reservatório, correspondente a afluência do rio Jaguaribe, que apresenta elevado aporte de materiais suspensos nas suas águas.

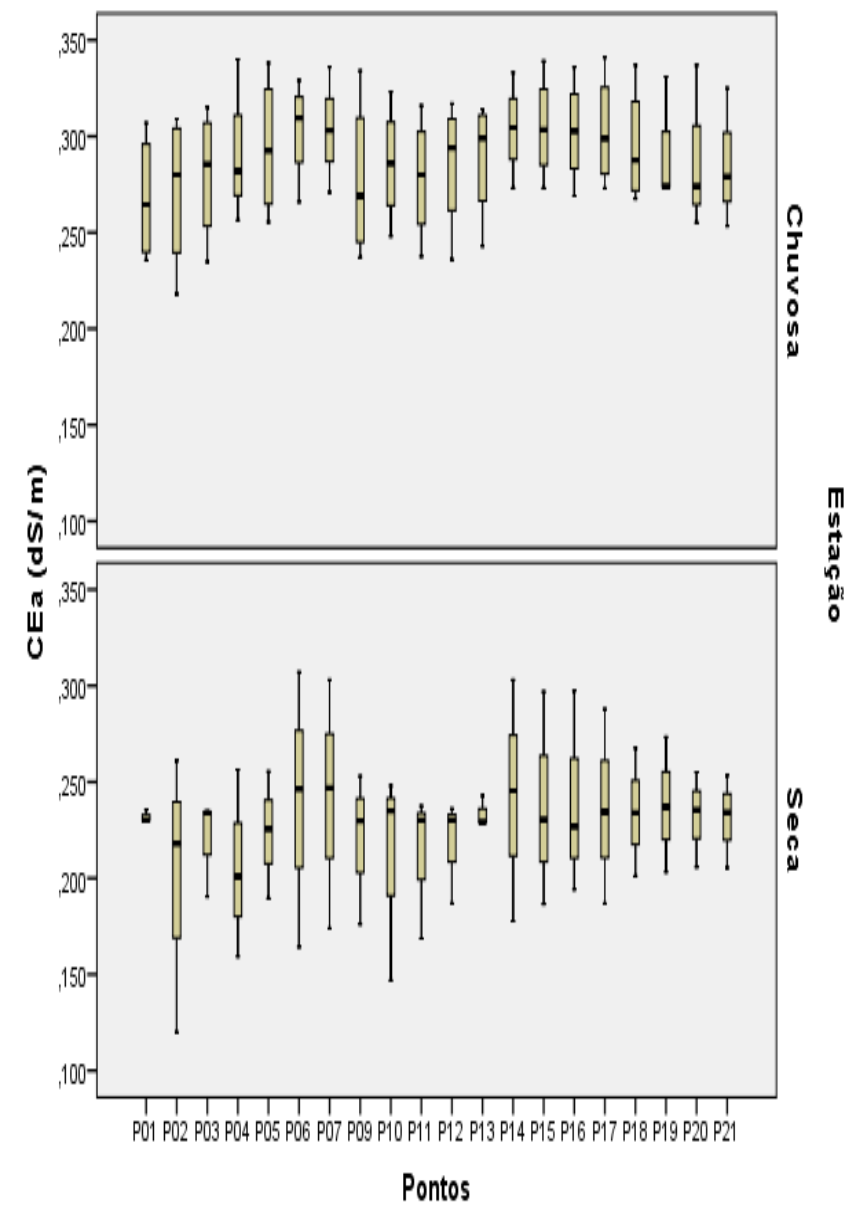

Figura 3. Variabilidade espacial da CEa para as águas do reservatório Orós, Ceará.

$\mathrm{Na}$ estação seca todos os pontos localizados na parte alta do reservatório (pontos: P01, P02, P03, P04, P05, P09, P10, P11, P12 e $\mathrm{P} 13)$ apresentaram mediana com tendência para a linha do quarto quartil, mostrando que houve menor variação dos valores em $50 \%$ das coletas, com concentrações mais altas, o que indica águas mais rasas e diluídas. Na estação chuvosa, apesar 
de menor variação comparando-se com a estação seca, observa-se valores mais elevados de salinidade, variando entre $0,2 \mathrm{dS} \mathrm{m}^{-1}$ e $0,35 \mathrm{dS} \mathrm{m}^{-1}$, isto em decorrência das altas precipitações pluviométricas (Figura 2). Já na estação seca os valores variaram entre $0,11 \mathrm{dS} \mathrm{m}^{-1}$ e $0,34 \mathrm{dS} \mathrm{m}^{-1}$. Valores semelhantes foram observados por, Barroso et al. (2011) avaliando a qualidade da água para irrigação na região Centro Sul no Estado do Ceará que teve valores da CE variantes entre $0,15 \mathrm{dS} \mathrm{m}^{-1}$ e $0,57 \mathrm{dS} \mathrm{m}^{-1}$. Este comportamento observado para o açude Orós pode ser explicado devido à degradação da mata ciliar as margens do açude no qual propicia um maior escoamento das águas na estação chuvosa, que carreiam elevadas concentrações de sais do solo, esses por sua vez se depositam no reservatório aumentando os níveis de salinidade (Figura 4). Pesquisadores como Gomes et al. (2007), Franco e Hernandez (2009), Vanzela et al. (2010) observaram que a ausência de matas ciliares para atividades agropecuárias favorece o transporte e a deposição de materiais sólidos nos mananciais, acarretando danos à qualidade das águas.

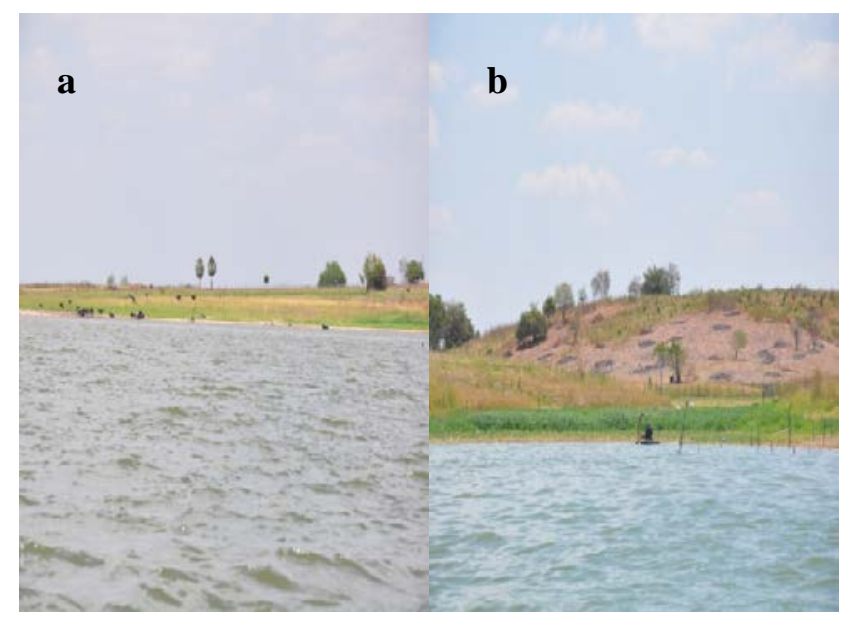

Figura 4. Usos inadequados dos recursos naturais: (a) Ausência de mata ciliar para a formação de pastagens e uso para o pastejo de bovinos em áreas nas proximidades do ponto P04 e (b) ausência de mata ciliar em decorrência ao desmatamento com o uso da prática de queimadas.
Na Figura 5 apresenta-se a variação temporal da salinidade das águas do açude Orós. Para as coletas do mês de março de 2011, houve uma maior variação, principalmente nos 25\% dos valores correspondentes ao primeiro quartil, com mediana tendendo para a linha do terceiro quartil, sendo o quarto quartil o que apresenta menor variação dos valores. As coletas do mês de agosto de 2011 e 2012 foram os que apresentaram menor variação, porém apresentaram valores discrepantes.

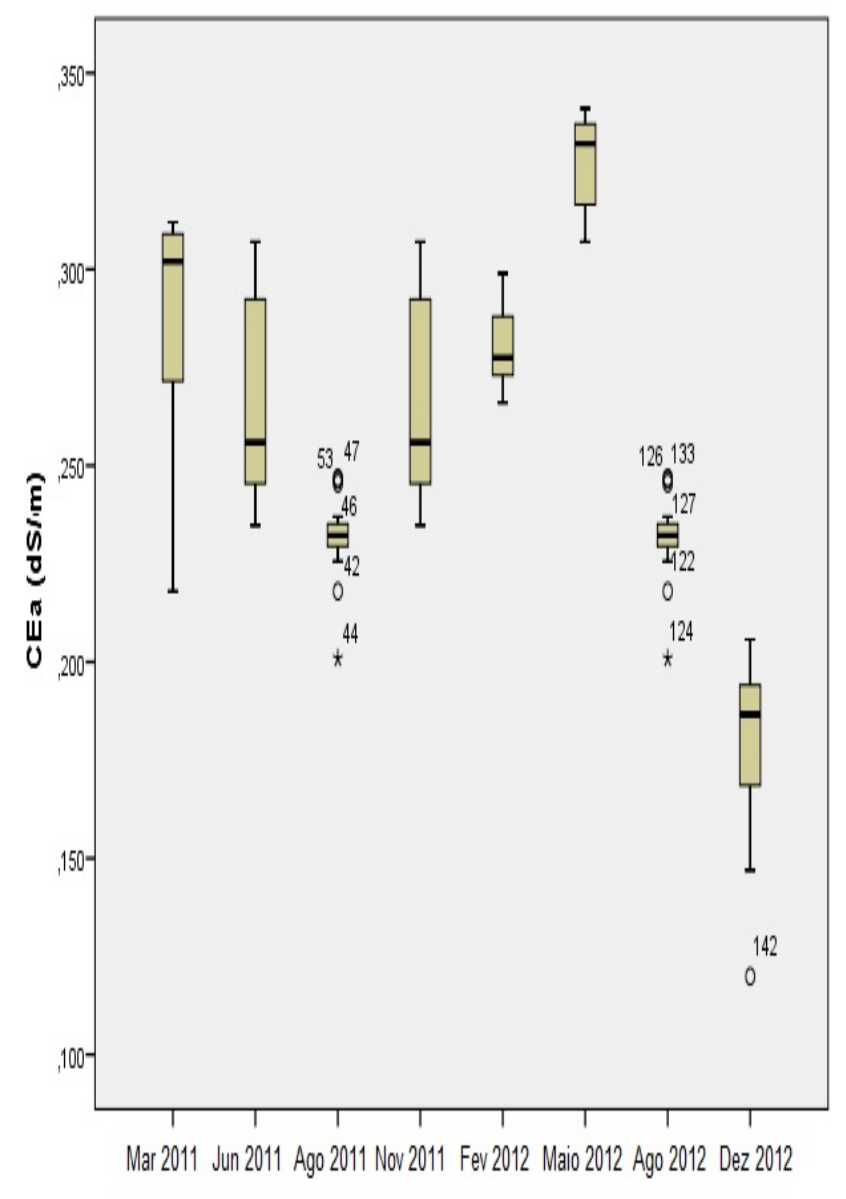

Mês

Figura 5. Variabilidade temporal da CEa para as águas do reservatório Orós, Ceará.

Os valores mais elevados foram encontrados na coleta de maio de 2012 correspondentes ao período chuvoso, e os menores na coleta de dezembro de 2012 correspondentes ao período de seca. Comportamentos semelhantes 
foram encontrados por Frota Júnior (2006), estudando a qualidade das águas no trecho perenizado da bacia hidrográfica do Curu, Ceará, no qual observou que as maiores concentrações de sais foram registradas no período chuvoso, e Lobato et al. (2008) estudando a Sazonalidade na qualidade da água de irrigação do Distrito Irrigado Baixo Acaraú, Ceará, no qual para estação chuvosa encontrou variação entre 0,12 $\mathrm{dS} \mathrm{m}^{-1}$ e $0,5 \mathrm{dS} \mathrm{m}^{-1}$ e para estação seca, variação entre $0,26 \mathrm{dS} \mathrm{m}^{-1}$ e $0,44 \mathrm{dS} \mathrm{m}^{-1}$, valores abaixo do limite para irrigação.

A variação espacial da RAS do açude Orós, no período seco e chuvoso, encontra-se na Figura 6. Verifica-se que os valores de RAS apresentaram sempre abaixo do limite para irrigação (RAS <3), segundo Ayers e Westcot (1999), porém com grande variação entre as estações. Resultados semelhantes foram encontrados por Lopes et al. (2014a) investigação da qualidade das águas de um grande reservatório na região semiárida do Brasil, onde as águas para uso na agricultura irrigada não apesentam risco de sodicidade visto que os valores médios da RAS foram inferiores ao limite que restringe a água para irrigação quanto a este parâmetro.

Para a estação seca foi observado pequena variações dos valores da RAS o que indica valores mais condensados (homogêneos), apresentando sempre próximos da mediana, variando de 0,7 a 1,1 . Diferente das variações verificadas na estação chuvosa, no qual apresenta uma maior amplitude das caixas, o que indica uma maior variação dos valores da RAS que foram entre 0,5 e 1,9 com mediana tendendo para a linha do primeiro quartil. Mesmo apresentando valores abaixo do limite, de acordo com Ayers e Westcot (1999) a interpretação da sodicidade das águas e dos problemas de infiltração, causados pela redução da permeabilidade devido ao efeito do sódio nas condições físicas do solo, depende dos valores da CE das águas.

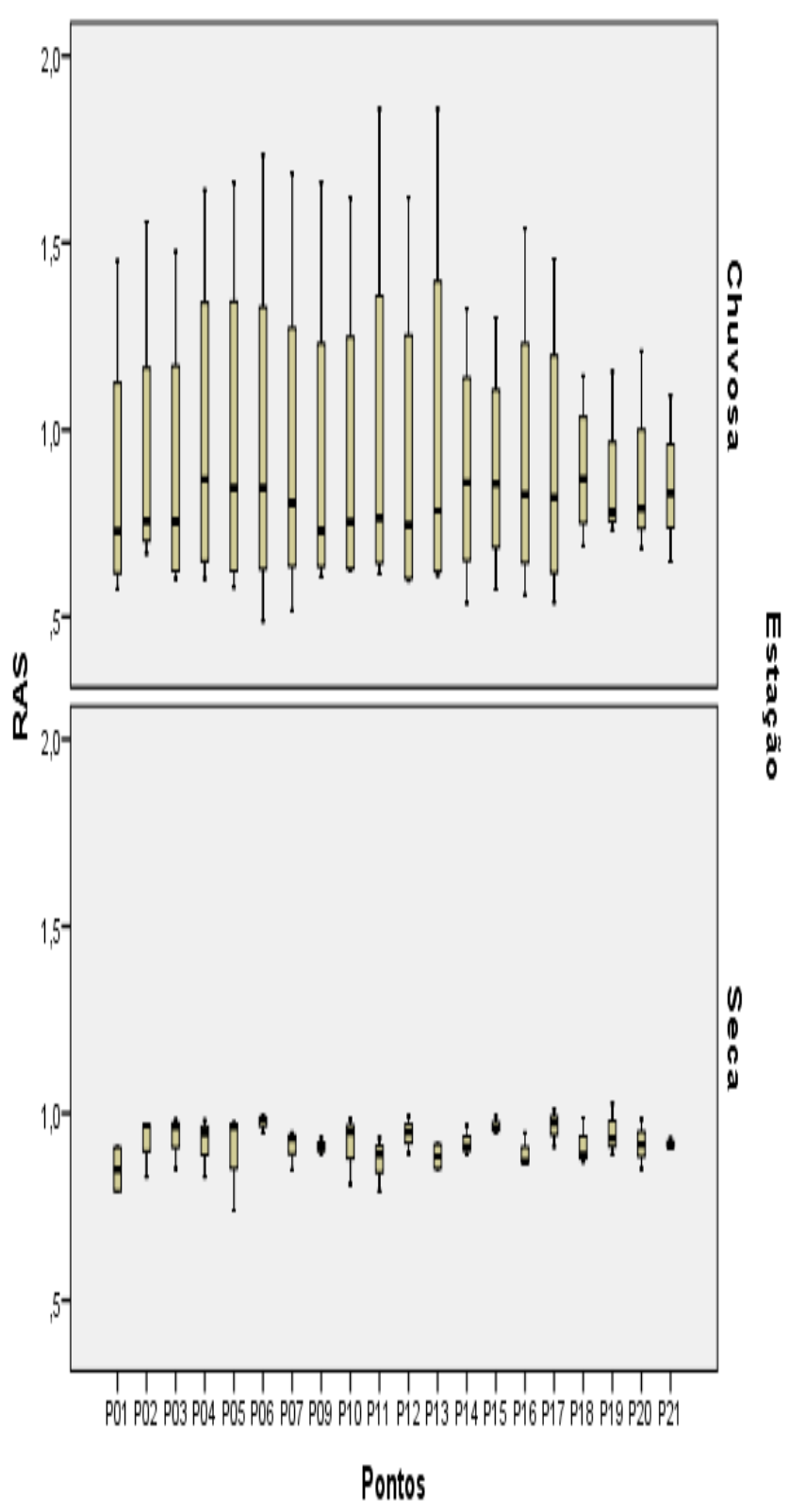

Figura 6. Variabilidade espacial da RAS para as águas do reservatório Orós, Ceará.

Analisando a variação temporal da RAS (Figura 7), observa-se uma maior variação no mês de maio de 2012, ao fim do período chuvoso (Figura 2), no qual segundo Lopes et al. (2007) pode ser justificado devido, no período chuvoso, ocorrer um aumento da drenagem superficial dos sais, e um maior aporte de efluentes das comunidades situadas às margens do açude. As demais coletas apresentaram pequena variação com valores entre 0,5 e 1,1 . 


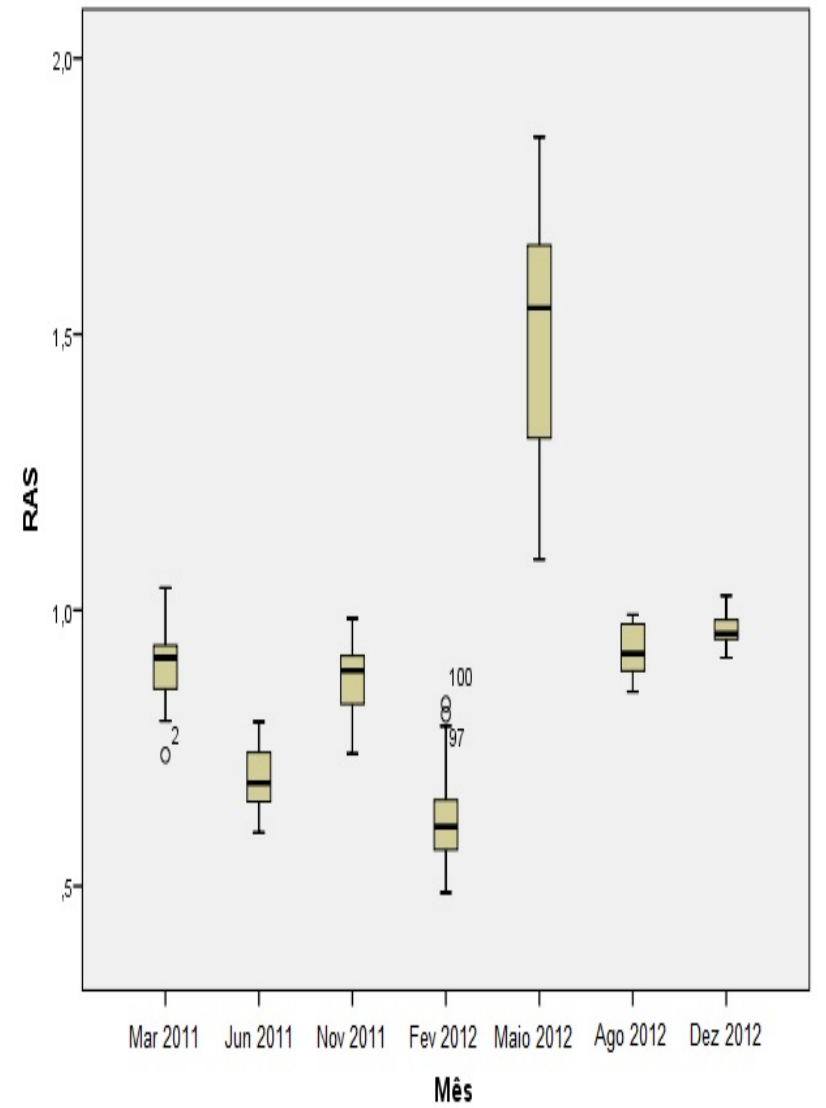

Figura 7. Variabilidade temporal da RAS para as águas do reservatório Orós, Ceará.

A Figura 8 apresenta a classificação da água para irrigação de acordo com a metodologia do Laboratório de Salinidade dos Estados Unidos (Richards, 1954). Observa-se que no período chuvoso as águas variaram entre as classes $\mathrm{C}_{1} \mathrm{~S}_{1}$ e $\mathrm{C}_{2} \mathrm{~S}_{1}$. Isto significa que as águas apresentaram risco de causar problemas de salinidade variando de baixo (podendo ser utilizada para irrigação da maioria das culturas, em quase todos os tipos de solo, com pouca probabilidade de que se desenvolvam problemas de salinidade) a médio (podendo ser usada sempre e quando houver uma lixiviação moderada de sais, estas se adequam a plantas moderadamente tolerantes a sais). Frota Junior (2006) também encontrou águas classificadas como de classe $\mathrm{C}_{2}$ estudando a qualidade das águas no trecho perenizado da bacia hidrográfica do Curu, Ceará. Quanto à sodicidade apresentaram-se como de baixo risco, podendo ser usada para irrigação na maioria dos solos, com pouca probabilidade de se atingir níveis perigosos de sódio trocável. Resultados semelhantes foram observados por Araújo Neto et al. (2010) nas águas superficiais do mesmo reservatório Orós, Ceará entre os anos de 2008 e 2009. Barroso et al. (2011) também observou resultados similares avaliando a qualidade da água para irrigação na região Centro Sul no Estado do Ceará, no qual afirma que essa variação pode ser atribuída ao regime irregular das chuvas, característica muito comum no semiárido nordestino.

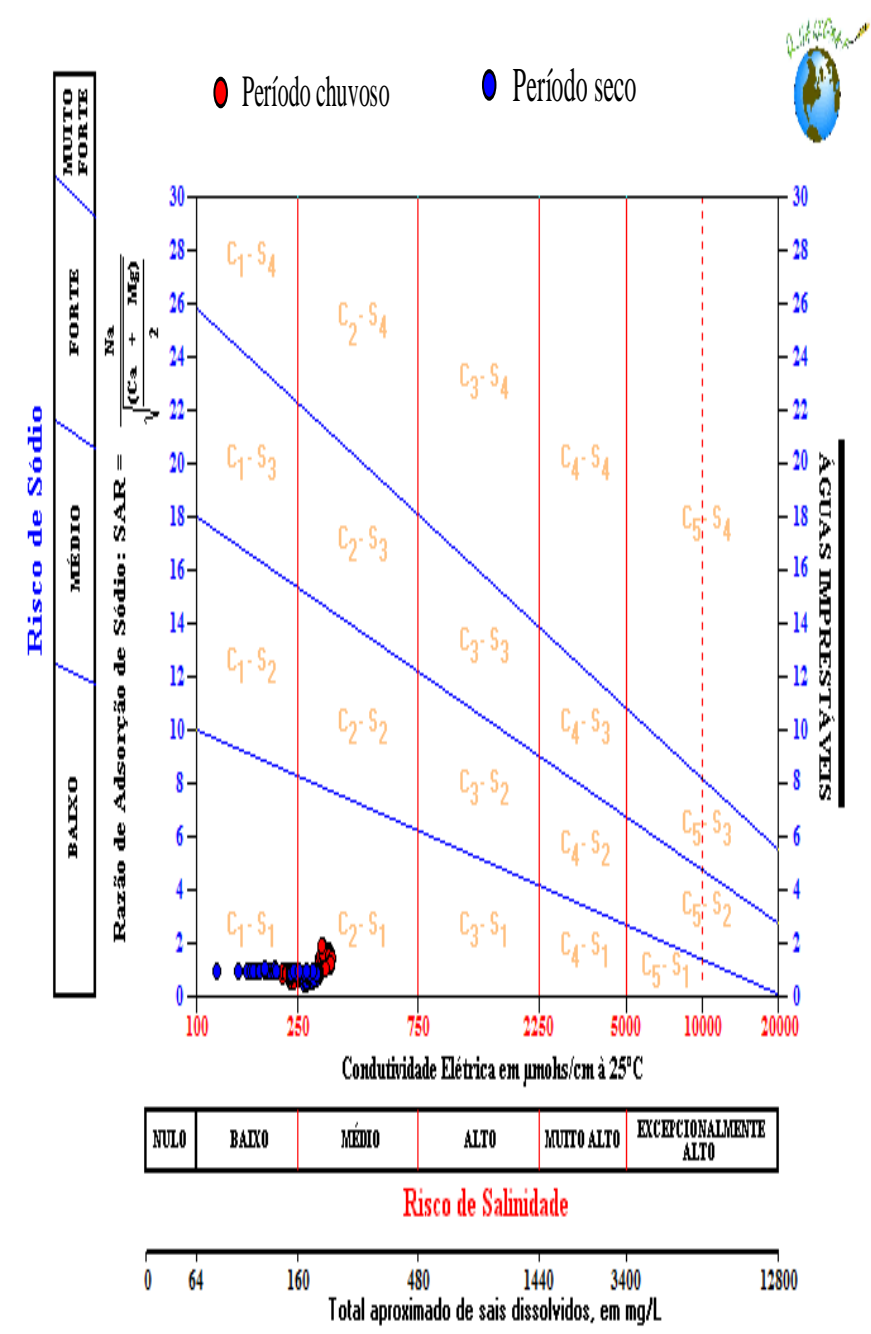

Figura 8. Classificação da água para fins de irrigação no reservatório Orós, Ceará.

Autores como Freire et al. (2003) apontam a necessidade de um controle criterioso da água usada na irrigação, principalmente quando a condutividade elétrica (CE) e relação de 
adsorção de sódio (RAS) apresentam valores baixos, águas classificadas como $\mathrm{C}_{1} \mathrm{~S}_{1}$ podem apresentar comportamento semelhante às águas $\mathrm{C}_{1} \mathrm{~S}_{5}$, quanto à velocidade de infiltração, em decorrência da dispersão dos colóides. Os resultados encontrados estão de acordo com Scaloppi e Britto (1986) e Meireles (2007), onde afirmam que águas com CE inferior a $0,5 \mathrm{dS} \mathrm{m}^{-1}$ e, particularmente, abaixo de $0,2 \mathrm{dS} \mathrm{m}^{-1}$ tendem a lixiviar os sais e minerais solúveis, incluindo os de cálcio, reduzindo sua influência sobre a estabilidade dos agregados e estrutura do solo. Desta forma, quando os problemas relativos à infiltração presentes em áreas irrigadas não são causados pelo efeito da RAS elevada, invariavelmente, são causados devido às águas de salinidade muito baixa.

Avaliando a sazonalidade da classificação das águas para irrigação quanto à salinidade, verifica-se que as coletas realizadas no período chuvoso apresentaram pontos com maiores concentrações de sais do que no período seco, mesmo comportamento foi verificado por Lobato et al. (2008), avaliando a qualidade da água de irrigação do Distrito Irrigado do Baixo Acaraú, Ceará. Como verificados anteriormente nos valores de $\mathrm{CE}$, essas maiores salinidades no período chuvoso ocorreram devido ao carreamento dos sais devido ao maior escoamento das águas na estação chuvosa.

\section{CONCLUSÕES}

1- As águas do reservatório apresentaram valores de salinidade sempre abaixo do limite para irrigação tanto no período seco como chuvoso;

2- A estação chuvosa, apesar de menor variação espacial entre os pontos de coletas em relação a estação seca, observa-se que ela apresentou valores mais elevados de salinidade devido ao carreamento dos sais em decorrência do maior escoamento no período chuvoso;

3- De acordo com a classificação do USDA para irrigação, os resultados mostraram que as águas do reservatório apresentaram, tanto no período seco como chuvoso, um risco de salinidade de baixo a médio e um risco de sodicidade baixo.

\section{AGRADECIMENTOS}

Os autores agradecem ao Instituto Nacional de Ciência e Tecnologia em Salinidade - INCTSal, ao Conselho Nacional de Desenvolvimento Científico e Tecnológico CNPq e a Coordenação de Aperfeiçoamento de Pessoal de Nível Superior - CAPES pelo apoio financeiro à pesquisa.

\section{REFERÊNCIAS}

APHA - American Public Health Association. Standard methods for the examination of water and wastewater. 21 ed. Washington, D.C. 2005.

ARAÚJO NETO, J. R.; MEIRELES, A. C.; PALÁCIO, H. A. Q.; ANDRADE, E. M.; LIMA, J. S. Caracterização hidroquímica e dinâmica qualitativa das águas superficiais do açude Orós para fins de irrigação. In: X SIMPÓSIO DE RECURSOS HÍDRICOS DO NORDESTE, Fortaleza, Ceará. Anais... ABRH, 2010.

\section{ARRAES, F. D. D. Dinâmica do balanço de energia na bacia hidráulica do açude Orós e suas adjacências. 2010. 31 f. Dissertação (Mestrado em Engenharia Agrícola) - Universidade Federal do Ceará, Fortaleza.}

AYERS, R. S.; WESTCOT, D.W. A qualidade 
da água na agricultura. 2.ed. Traduzido por GHEYI, H. R.; MEDEIROS, J. F.; DAMASCENO, F. A. V. Campina Grande: UFPB, 1999. 218p. (Estudos FAO: Irrigação e Drenagem, 29).

BARROSO, A. A. F.; GOMES, G. E.; LIMA, A. E. O.; PALÁCIO, H. A. Q.; LIMA, C. A. Avaliação da qualidade da água para irrigação na região centro sul no estado do Ceará. Revista Brasileira de Engenharia Agrícola e Ambiental. v.15, n.6, p.588-593, 2011.

DNOCS - Departamento Nacional de Obras Contra as Secas. Barragem Presidente Juscelino Kubitschek de Oliveira. Disponível em: <http://www.dnocs.gov.br/barragens/oros/ oros.htm> Acesso em: 14 jan. 2014.

EMBRAPA - Empresa Brasileira de Pesquisa Agropecuária Solos. Sistema Brasileiro de Classificação de Solos. 2 ed. Brasília, DF. 2006.

FRANCO, R. A. M.; HERNANDEZ, F. B. T. Qualidade da água para irrigação na microbacia do Coqueiro, estado de São Paulo. Revista Brasileira de Engenharia Agrícola e Ambiental, v. 13, n. 6, p. 772-780, 2009.

FREIRE, M. B. G.S.; RUIZ, H. A.; RIBEIRO, M. R.; FERREIRA, P. A.; ALVAREZ, V. H.; FREIRE, F.J. Estimativa o risco de sodificação de solos de Pernambuco pelo uso de águas salinas. Revista Brasileira de Engenharia Agrícola e Ambiental, v.7, n.2, p.227-232, 2003.

FROTA JÚNIOR, J. I. Variabilidade espacial e temporal da qualidade das águas no trecho perenizado da bacia hidrográfica do Curu, Ceará. 2006. 51f. Dissertação (Mestrado em Engenharia Agrícola) - Universidade Federal do Ceará, Fortaleza.

FUNCEME - Fundação Cearense de Meteorologia e Recursos Hídricos. Séries históricas. Disponível em: <http://www.funceme.br/produtos/script/chuvas/
Download_de_series_historicas/downloadHistori cos/postos/58.txt>. Acesso em: 12 jan. 2014.

FUNCEME - Fundação Cearense de Meteorologia e Recursos Hídricos. Qualigraf. Disponível em: <http://www.funceme. br/dehid/index.htm>. Acesso em: 13 mar. 2013.

GOMES, N. M.; FARIA, M. A.; SILVA, A. M.; MELLO, C. R.; VIOLA, M. R. Variabilidade espacial de atributos físicos do solo associados ao uso e ocupação da paisagem. Revista Brasileira de Engenharia Agrícola e Ambiental, v. 11, n. 4, p. 427-435, 2007.

LOBATO, F. A. O.; ANDRADE, E. M.; MEIRELES, A. C. M.; CRISOSTOMO, L. A. Sazonalidade na qualidade da água de irrigação do Distrito Irrigado Baixo Acaraú, Ceará. Revista Ciência Agronômica, v. 39, n. 01, p. 167-172,2008.

LOPES, F. B.; ANDRADE, E. M.; MEIRELES, A. C. M.; BECKER, H.; BATISTA, A. A. Assessment of the water quality in a large reservoir in semiarid region of Brazil. Revista Brasileira de Engenharia Agrícola e Ambiental, v. 18, p. 437-445, 2014a.

LOPES, F. B.; TEIXERA, A. S.; ANDRADE, E. M.; AQUINO, D. N.; ARAÚJO, L. de F. P. Mapa da qualidade das águas do rio Acaraú, pelo emprego do IQA e Geoprocessamento. Revista Ciência Agronômica, v. 39, p. 392-402, 2008.

LOPES, F.B.; BARBOSA, C. C. F.; NOVO, E. M. L. M.; ANDRADE, E. M.; CHAVES, L. C. G. Modelagem da qualidade das águas a partir de sensoriamento remoto hiperespectral. Revista Brasileira de Engenharia Agrícola e Ambiental, v. 18, p. 13-19, 2014b.

LOPES, J. F. B; ANDRADE, E. M.; LOPES, F. B.; AQUINO, D. N. Variabilidade e risco de sodicidade do solo pela utilização das águas superficiais da bacia do Curu, Ceará, Brasil. In: XXXVI CONGRESSO BRASILEIRO DE 
ENGENHARIA AGRÍCOLA, Bonito - MS. Laboratory Staff, 160p, 1954.

Anais... 2007. p. 1-4.

MEIRELES, A. C. M. Dinâmica qualitativa das águas superficiais da bacia do Acaraú e uma proposta de classificação para fins de irrigação. 2007. 180 f. Tese (Doutorado em Recursos Hídricos) - Universidade Federal do Ceará, Fortaleza.

RICHARDS, L. A. Diagnosis and improvement of saline and alkali solis. Washington, DC: United States Salinity
SCALOPPI, E. D.; BRITTO, R. A. L. Qualidade da água e do solo para irrigação . Informe Agropecuário, Belo Horizonte, v.139, p.80-94, 1986.

VANZELA, L. S.; HERNANDEZ, F. B. T; FRANCO, R. A. M. Influência do uso e ocupação do solo nos recursos hídricos do Córrego Três Barras, Marinópolis. Revista Brasileira de Engenharia Agrícola e Ambiental, v. 14, n. 1, p. 55-64, 2010. 